\section{Anatomical Differences of Axillary Bud Development in Blind Nodes and Normal Nodes in Peach}

\author{
Unaroj Boonprakob ${ }^{1}$ and David H. Byrne ${ }^{2}$ \\ Department of Horticultural Sciences, Texas A\&M University, College Station, \\ TX 77843-2133
}

Dale M.J. Mueller ${ }^{2}$

Department of Biology, Texas A\&M University, College Station, TX 77843-3258

Additional index words. blind wood, deformed bud, bud failure, Prunus persica

\begin{abstract}
Actively growing shoots of peach [Prunus persica (L.) Batsch] were collected every 2 weeks throughout the 1989 growing season. The samples were sectioned longitudinally and transversely to observe axillary bud initiation, which occurred in all samples collected. Differentiation of axillary bud meristems from early season samples (mostly normal nodes) included apical and prophyll formation, with procambium connected to the stem procambium. Little to no differentiation of such structures occurred in the lateseason samples (mostly blind nodes). Other results suggest that blind node formation is a consequence of a lack of bud differentiation rather than a failure of bud initiation.
\end{abstract}

The lack of axillary growth at the axils of primary peach leaves was described as blind nodes (Blake, 1943; Dorsey, 1935) and as undeveloped buds (Faust, 1989). Blind nodes on peach are noticeable in summer as an absence of axillary buds, commonly on the basal and terminal portion of a current-season shoot. Blind nodes may be mistaken as bud drop (Weinberger, 1967) or bud failure (Malcolm, 1975) in winter. The latter two cases have buds developed fully before dropping. The bud drop or bud failure symptom in peaches is similar to bud failure symptom in almonds [Prunus dulcis (Mill.) Webb.] reported by Kester and Jones (1970). However, bud drop in peaches occurs with reproductive buds and may be caused by insufficient chilling during the winter (Weinberger, 1967), whereas bud failure in almonds occurs with vegetative buds as a result of high-temperature sensitivity (Kester and Asay, 1975).

An excessive number of blind nodes $(>50 \%)$ were observed on several peach cultivars in the southern United States (Boonprakob et al., 1994; Richards et al., 1994). Moderate blind node formation in peaches is frequently inconsequential because a peach typically produces an excessive number of flowers. A commercial crop requires about a 5\% flower set. Therefore, even though 50\% of the nodes may be blind, economic production is reached. Additionally, fewer blind nodes occur in more northern production areas. Nevertheless, ex-

\footnotetext{
Received for publication 21 Dec. 1995. Accepted for publication 25 Apr. 1996. The cost of publishing this paper was defrayed in part by the payment of page charges. Under postal regulations, this paper therefore must be hereby marked advertisement solely to indicate this fact.

${ }^{1}$ Graduate Student.

${ }^{2}$ Associate Professor.
}

cessive blind nodes can be of concern. In areas of high risk of spring frost, a cultivar with few flower buds has greater risk of an economically important level of flower bud freeze damage (Werner et al., 1988). Blind nodes may limit shoot formation, impacting critical tree training and pruning procedures in young trees, and because blind nodes lack a vegetative bud, they cannot be used as a budwood source for asexual propagation. The objective of the study was to describe the anatomical basis of blind node formation compared to formation of normal nodes.

\section{Materials and Methods}

Actively growing shoot tips $\approx 2.0 \mathrm{~cm}$ long were collected every 2 weeks from 'EarliGrande' and 'June Gold' peach trees in a research orchard at Texas A\&M Univ. near College Station. The samples were collected from the earliest growth in spring (March) to latest growth in summer (August) in 1989. They then were divided into two groups: early season growth (March, April, and May) and late-season growth (June, July, and August) based on observations that most nodes formed during March, April, and May were normal and most nodes formed later were blind.

Samples were killed and fixed in formalinacetic-alcohol (FAA) solution, dehydrated with tertiary butyl alcohol, infiltrated, and embedded using paraffin (Johansen, 1940) with the following modifications: samples were transferred from FAA to a series of ethyl alcohol concentrations at $75 \%, 90 \%$, and four times with absolute ethyl alcohol, each step for $8 \mathrm{~h}$ under vacuum; they then were transferred to a series with tertiary butyl alcohol diluted with absolute ethyl alcohol at $75 \%, 95 \%$, and four times at $100 \%$, each step for $8 \mathrm{~h}$ at $56^{\circ} \mathrm{C}$. Serial longitudinal and transverse sections were cut
$10-15 \mu \mathrm{m}$ in thickness on a rotary microtome (model 820; American Optical, Buffalo, N.Y.). Sections were affixed to slides, stained with safranin-fast green, and examined using a light microscope (Zeiss, West Germany). Selected sections were photographed and pertinent structural features described.

\section{Results and Discussion}

The initiation of axillary bud formation from the apical meristem of the shoot was not identified in this study. However, the initiation of an axillary bud in peaches likely occurs as a detached meristem (Esau, 1960; Mauseth, 1988), because Dermen's (1953) work indicated that anatomy of an axillary bud in peach could be traced back to the apical meristem's layers. In this study, the early structure of axillary bud meristems of 'EarliGrande' and 'June Gold' was observed in transverse and longitudinal sections as small mounds of meristematic cells in the axil of a developing leaf. The bud meristem could be identified by the development of procambial strands from the parent shoot into the bud. The origin of axillary bud meristems took place close to the shoot apex in early season growth samples, some as close as $15-30 \mu \mathrm{m}$ below the apical dome (Fig. 1A).

Well-developed axillary bud meristems were present at most nodes in early season shoots. The degree of development was greater in buds located farther from the shoot apex. At a distance $<400 \mu \mathrm{m}$ below the shoot apex, the axillary bud meristem had already developed prophylls (Fig. $1 \mathrm{~B}$ and C). The procambium of axillary buds was well connected with the procambium of the stem (Fig. 1D). Samples collected during the early part of the growing season showed that axillary buds had developed extensively and had produced prophylls (Fig. 1E) at less than $2 \mathrm{~mm}$ below the shoot apex. Thus, after the initiation of axillary bud meristem in early season samples, subsequent rapid development involved enlargement and differentiation of axillary bud meristems, as well as the organization of cells into more specialized tissues.

In contrast, samples collected late in the growing season had only the rudiments of meristematic activity in leaf axils close to the shoot apices (Figs. 1F and 2A); nevertheless, axillary bud initiation and early development had occurred. These axillary bud meristems were situated farther ( 110 and $165 \mu \mathrm{m})$ below the apical dome than those in early season samples. After initiation, bud meristem development in late-season samples was very limited (Fig. 2 B and C). Very few of the axillary meristems in late-season samples had developed prophylls. At a greater distance below the apical dome, axillary buds were rarely observed; rather, there were typically only empty leaf axils with only partial development of the stem procambium towards the position of the aborted axillary buds (Fig. 2D). These were blind nodes.

Axillary bud meristems were initiated in samples collected early and late in the growing season, although the pattern of development 

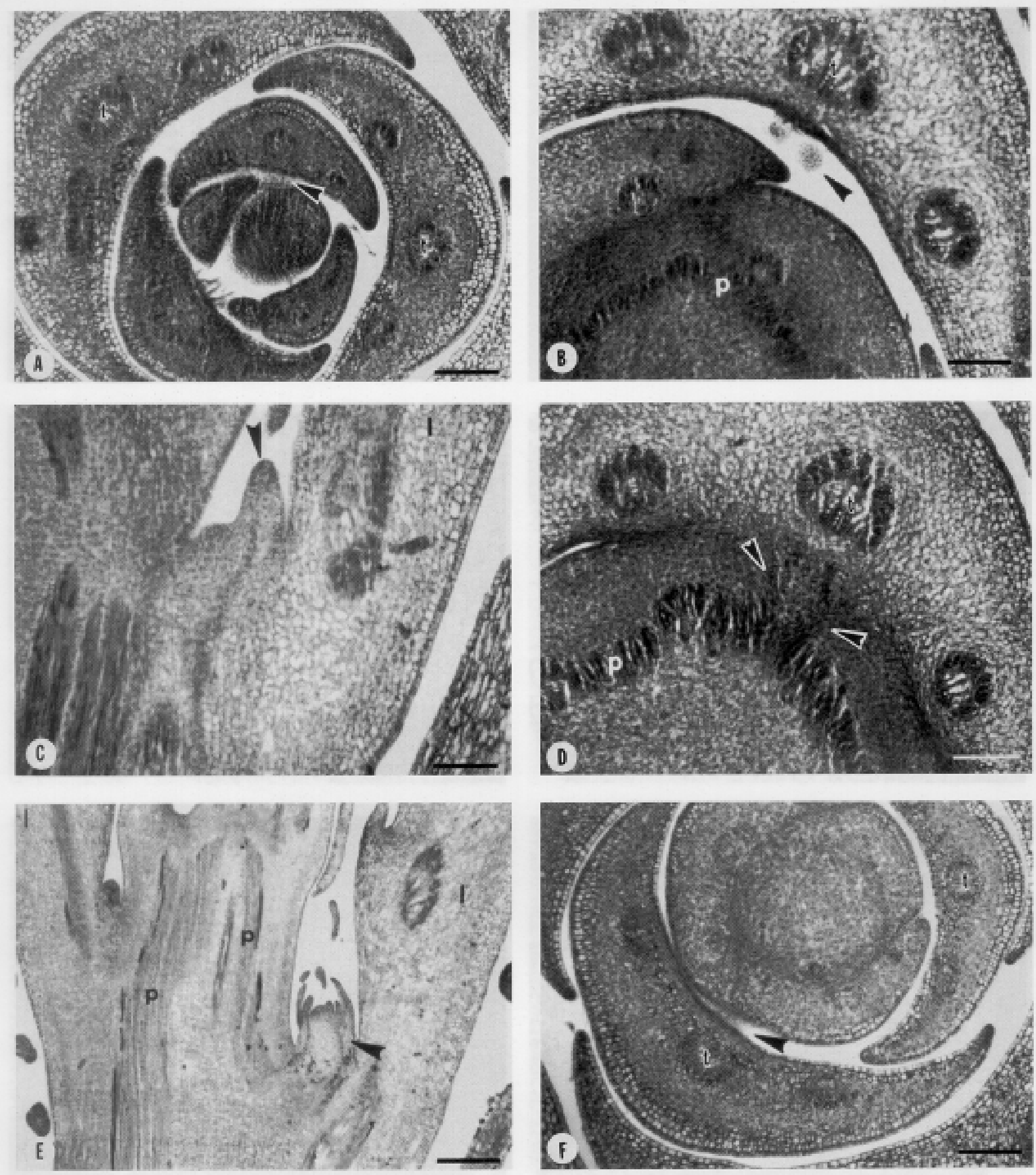

Fig. 1. (A and B) Transverse sections of 'EarliGrande' peach shoot collected on 9 Apr. 1989 (early season sample). (A) A mound of the axillary bud meristem (arrowhead) at $15 \mu \mathrm{m}$ below the shoot apex. (B) Tip of a developing prophyll (arrowhead) on the axillary bud meristem, at $120 \mu \mathrm{m}$ below the shoot apex. (C and E) Longitudinal section of 'June Gold' peach shoot collected on same day (early season sample). (C) Prophyll (arrowhead) development from the axillary bud meristem that was located $\approx 540 \mu \mathrm{m}$ below the shoot apex for a section $320 \mu \mathrm{m}$ off the median plane. The axillary bud (arrowhead) had developed as an apical meristem with prophylls. (E) The bud was $\approx 1.48 \mathrm{~mm}$ below the shoot apex and the section was $350 \mu \mathrm{m}$ off the median plane. Transverse sections of 'EarliGrande' shoot collected (D) on same day (early season sample) and (F) on 24 July 1989 (late-season sample). (D) The oblique path of the procambium (arrowhead) between the axillary bud and the stem is shown for a section $255 \mu \mathrm{m}$ below the shoot apex. (F) A small mound of axillary bud meristem (arrowhead) at $165 \mu \mathrm{m}$ below the shoot apex. The crescent shapes are developing leaves. Abbreviations: $(\mathbf{A}, \mathbf{B}$, and $\mathbf{D}) \mathrm{t}=$ leaf trace, $\mathrm{p}=\operatorname{procambium} ;(\mathbf{E}) \mathrm{p}=\operatorname{protophloem}$ and protoxylem, $1=$ developing leaf. Bars $=0.1 \mathrm{~mm}(\mathbf{A}-\mathbf{D}$ and $\mathbf{F}), 0.3 \mathrm{~mm}(\mathbf{E})$. 


\section{Crop Production}
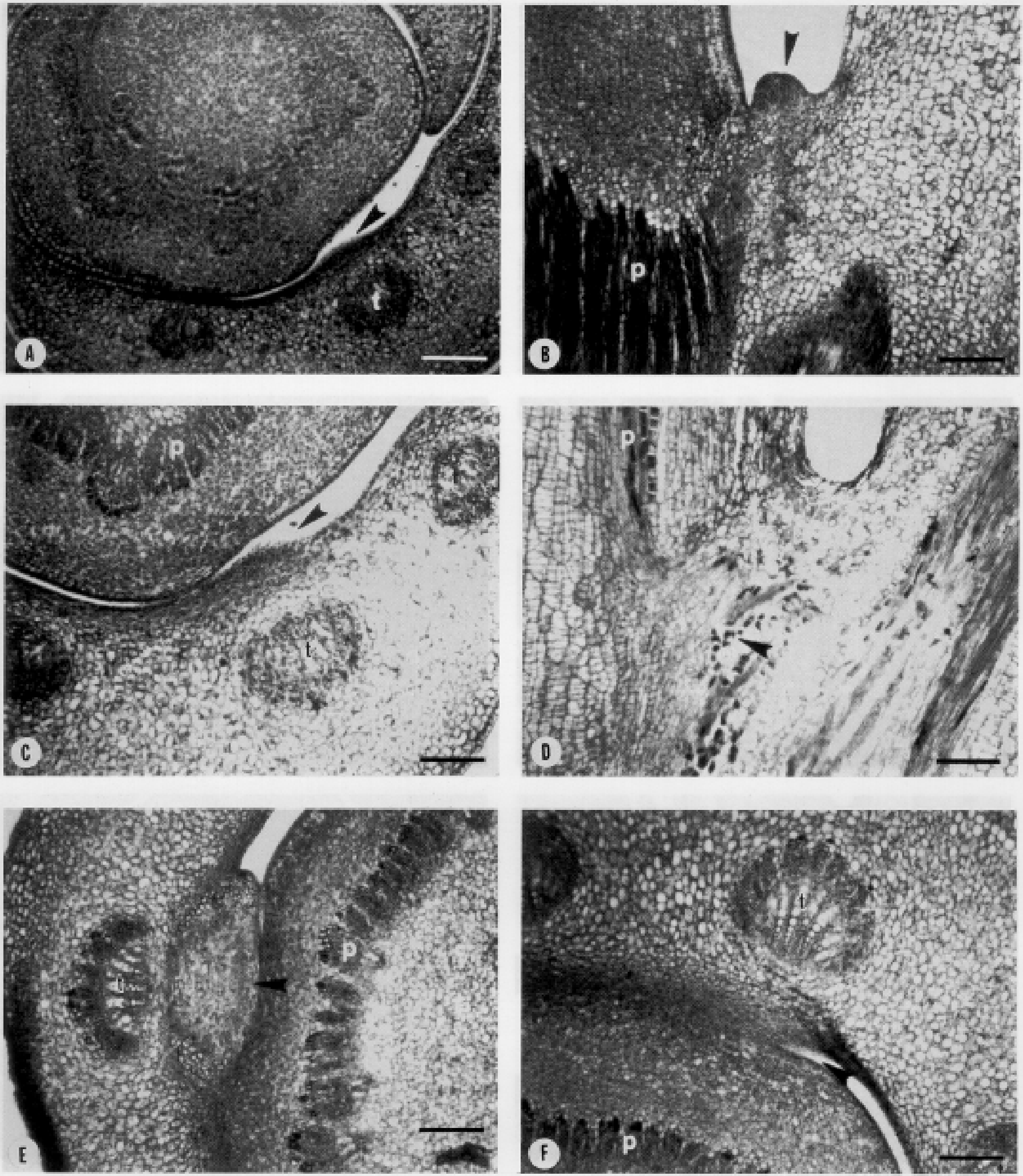

Fig. 2. (A and C) Transverse section of 'June Gold' peach shoot collected on 24 July 1989 (late-season sample). (A) A small mound of axillary bud meristem (arrowhead), at $110 \mu \mathrm{m}$ below the apical dome. (C) The small axillary bud meristem (arrowhead) $440 \mu \mathrm{m}$ below the shoot apex. (B) Longitudinal section of 'EarliGrande' peach shoot collected on same day (late-season sample) showing a small mound of axillary bud meristem (arrowhead) without prophyll development. The axillary bud meristem was $\approx 0.8 \mathrm{~mm}$ below the shoot apex. The section was $360 \mu \mathrm{m}$ off the median plane. (D) Longitudinal section of 'June Gold' shoot collected on 4 June 1989 (late-season sample) showing an empty leaf axil (blind node) with acropetal development of stem procambium (arrowhead) toward the site of the aborted axillary bud. The shoot's leaf is to the right. (E) Transverse section of 'EarliGrande' shoot collected on 9 Apr. 1989 (early season sample) showing well developed axillary bud (arrowhead) $430 \mu \mathrm{m}$ below the shoot apex. (F) Transverse section of 'EarliGrande' shoot collected on 24 July 1989 (late-season sample) showing limited development of the axillary bud meristem (arrowhead) $960 \mu \mathrm{m}$ below the shoot apex. Abbreviations: $\mathrm{t}=$ leaf trace, $\mathrm{p}=$ protophloem and protoxylem. Bars $=0.1 \mathrm{~mm}$. 
differed. In samples from early season growth, axillary bud meristems could be identified closer to the parent shoot apex than could those from late-season growth. Prophyll development from axillary bud meristems was observed frequently in early but not in lateseason samples. Early season samples had predominantly normal, well-developed axillary buds (Fig. 2E), whereas the late-season samples had mostly blind nodes with poorly developed or no axillary buds (Fig. 2F).

Blind nodes differ from bud drop (Weinberger, 1967) or bud failure (Malcolm, 1975 ) in that the meristem is only initiated but does not develop, whereas with bud drop and bud failure the bud is fully developed and later abscises. It follows that the critical developmental step in blind node formation occurs during the initial step of bud initiation and formation during the summer months (Raseira and Moore, 1987) and not during the later stages of development (dormancy and budbreak), as is the case with bud drop and bud failure. It is at this early stage of bud development that field management strategy should be focused.

The frequency of blind nodes is related to the genotype as well as environmental factors (Boonprakob et al., 1994; Richards et al., 1994). Observations in Texas, Florida, and Mexico indicate that high temperature during flower bud initiation and development during the summer months are associated with a greater frequency of blind nodes. Thus, the expression of this trait seems to be increased by stress during bud initiation and development, as is the case with the formation of twin or double fruit in stone fruit (Diaz et al., 1986; Patten et al., 1989; Southwick et al., 1991). The alleviation of the high-temperature stress by ensuring an adequate water supply mini- mized double fruit formation with peach (Patten et al., 1989) and should be explored as a management strategy to minimize blind node formation. Although this strategy may minimize this problem with the current cultivars, given the wide variability documented in the propensity to form blind nodes in peach germplasm (Boonprakob et al., 1994; Richards et al., 1994), the selection against high blind node development in the creation of new cultivars appears to be possible and should be pursued.

In conclusion, both the normal bud (early season samples) and bud of blind nodes (lateseason samples) initiate bud meristems, as evidenced by small mounds of meristematic cells in the leaf axil of both sample sets. The difference lies in the subsequent development of the two classes of buds. Whereas normal axillary buds develop apical and prophyll formations and normal procambium connection to the stem procambium, blind nodes have very limited subsequent development of axillary buds. A blind node in peach may be described anatomically as a node having no bud in its leaf axil, although the node retains the procambial traces to the site of the aborted bud.

\section{Literature Cited}

Blake, M.A. 1943. Classification of fruit bud development on peaches and nectarines and its significance in cultural practice. New Jersey Agr. Expt. Sta. Bul. 706.

Boonprakob, U., D.H. Byrne, and R.E. Rouse. 1994. A method for blind node evaluation. Fruit Var. J. 48:101-103.

Dermen, H. 1953. Periclinal cytochimeras and origin of tissues in stem and leaf of peach. Amer. J. Bot. 40:154-168.

Diaz, D.H., J.J. Martinez, and W.B. Sherman. 1986.
Apple and peach production in warm climates of northwest Mexico. Fruit Var. J. 40:121-125.

Dorsey, M.J. 1935. Nodal development of peach shoot as related to fruit bud formation. Proc. Amer. Soc. Hort. Sci. 33:245-257.

Esau, K. 1960. Anatomy of seed plants. Wiley, New York.

Faust, M. 1989. Physiology of temperate zone fruit trees. Wiley, New York.

Johansen, D.A. 1940. Plant microtechnique. McGraw-Hill, New York.

Kester, D.E. and R. Asay. 1975. Almonds, p. 387419. In: J. Janick and J.N. Moore (eds.). Advances in fruit breeding. Purdue University Press, West Lafayette, Ind.

Kester, D.E. and R.W. Jones. 1970. Noninfectious bud-failure from breeding programs of almonds (Prunus amygdalus Batsch). J. Amer. Soc. Hort. Sci. 95:492-496.

Malcolm, H.D.R. 1975. Bud failure of stone fruitSome changes in development and chemical composition of the flower buds of peach. J. Proc. Royal Soc. New South Wales 108:189-202.

Mauseth, J.D. 1988. Plant anatomy. Benjamin/ Cummings, Menlo Park, Calif.

Patten, K., G. Nimr, and E. Neuendorff. 1989. Fruit doubling of peaches as affected by water stress. Acta Hort. 254:319-321.

Raseira, M.C.B. and J.N. Moore. 1987. Time of flower bud initiation in peach cultivars differing in chilling requirement. HortScience 22:216-218.

Richards, G.D., G.W. Porter, J. Rodriguez-A, and W.B. Sherman. 1994. Incidence of blind nodes in low-chill peach and nectarine germplasm. Fruit Var. J. 48:199-202.

Southwick, S.M., K.A. Shackel, J.T. Yeager, W.K. Asai, and M. Katacich. 1991. Over-tree sprinkling reduces abnormal shapes in 'Bing' sweet cherries. Calif. Agr. 45:24-26.

Weinberger J.H. 1967. Studies on flower bud drop in peaches. Proc. Amer. Soc. Hort. Sci. 91:78-83.

Werner, D.J., B.D. Mowrey, and J.X. Chaparro. 1988. Variability in flower bud number among peach and nectarine cultivars. HortScience 23:578-580. 